\title{
Endoscopic visualisation of the human nasolacrimal system: an experimental study
}

\author{
A D Singh, A Singh, I Whitmore, E Taylor
}

\begin{abstract}
Orthograde and retrograde endoscopy of the upper and lower nasolacrimal system was performed using two prototype ultrathin (0.5 $\mathrm{mm}$ and $1.1 \mathrm{~mm}$ diameter) fibrescopes on four cadaver heads. Appearances were verified by subsequent dissection. The procedure, which we term 'dacryocystoscopy' is described. With modifications this technique may have clinical applications in the treatment of nasolacrimal disorders.
\end{abstract}

(Brf Ophthalmol 1992; 76: 663-667)

Thorpe ${ }^{1}$ was the first to describe the ophthalmic application of an endoscope in 1934 for the removal of intravitreal non-magnetic foreign bodies. With the advent of fibreoptics, flexible and fine calibre endoscopes could be designed and Norris ${ }^{2-4}$ adapted a $1.7 \mathrm{~mm}$ fibreoptic endoscope for both intraocular and orbital surgery. More recently a new generation of electronic videoendoscopes has become commercially available for gastrointestinal endoscopy. ${ }^{5}$ Instead of fibreoptics these endoscopes are based on a charge-coupling device (CCD). The image from the tip of the endoscope is focused on a CCD that transmits the image electronically via a video system to the television monitor. As the image is stored digitally this offers potential capability of image enhancement and computer analysis. A new ophthalmic electronic videoendoscope system for intraocular surgery with a 20 gauge $\left(0.89 \mathrm{~mm}\right.$ diameter) probe has been designed. ${ }^{6}$ This helps to visualise the pars plana, ciliary body, and the posterior surface of the iris.

Endoscopy of the nasolacrimal system has been reported previously with rigid and semirigid endoscopes. ${ }^{78}$ Ashenhurst and Hurwitz ${ }^{8}$ developed a prototype lacrimal endoscope (canaliculoscope) and used it to visualise the canaliculus and lacrimal sac. Following a recent report $^{9}$ on salivary gland endoscopy using 0.8 $\mathrm{mm}$ ultrafine diameter fibrescope (endoscope based on fibreoptics) we decided to investigate the feasibility of endoscopic visualisation of the entire nasolacrimal system using prototype fibrescopes on cadavers and to confirm the appearances by dissection.

\section{Material and methods}

Four embalmed cadaveric heads were made available at the Department of Anatomy, Queen Mary and Westfield College. The upper nasolacrimal system was studied in two specimens. To study the lower system (lacrimal sac and nasolacrimal duct) sagittal sections of the head (two) were used. The nasal septum and the inferior turbinate were removed to visualise the opening of the nasolacrimal duct into the inferior meatus.

Two prototype ultrathin fibrescopes PF-5 and XTUF-11 (Olympus Co Ltd, Tokyo) were used. The PF-5 fibrescope has an outer diameter of $0.5 \mathrm{~mm}$, is forward viewing, with a depth of field of 3 to $50 \mathrm{~mm}$ (Fig 1). The XTUF-11 fibrescope has an outer diameter of $1.1 \mathrm{~mm}$ and has an instrument channel $0 \cdot 1 \mathrm{~mm}$ wide. The depth of field is similar to the PF-5 fibrescope. Both instruments have a 60 degree field of view. CLV-10 OES was used as the light source. The fibrescope was attached to a compact colour video camera (Olympus OTV-F2) which measures $17 \mathrm{~mm} \times 48 \mathrm{~mm}$ and weighs $20 \mathrm{~g}$. This produces high resolution images even in low light conditions. This was coupled to a portable CCTV unit (Olympus PVS-1) combining a 9 inch monitor and Video8 VTR; this provided a display of the magnified images during the length of the procedure. The magnification from the fibrescope to the PVS-1 monitor is by a factor of $1 \cdot 7$. A continuous recording was made and at the end of each procedure the tapes were analysed and selected images were printed.

\section{UPPER NASOLACRIMAL SYSTEM (ORTHOGRADE} ENDOSCOPY)

After dilatation of the punctum, graduated silver probes (' 0 ' to ' 3 ' John Weiss) were inserted to dilate the upper canaliculus. After flushing the nasolacrimal system with normal saline using a syringing canula, healon was injected to keep the structures dilated so as to facilitate introduction

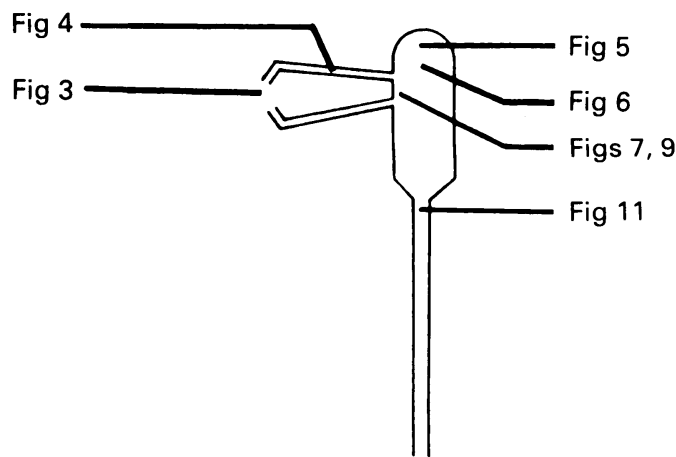

Figure 2 The positions of the fibrescope tip in the following figures. 
of the fibrescopes. The PF-5 fibrescope could be introduced easily into the canaliculus up to the level of the lacrimal sac. Greater dilatation with a size ' 3 ' silver probe was required before the thicker XTUF-11 fibrescope could be introduced. Neither of the fibrescopes could be manipulated to enter the upper opening of the nasolacrimal duct owing to the rigidity of the embalmed cadaveric tissues and extreme flexibility of the fibrescopes. Both fibrescopes provided adequate visualisation of the upper nasolacrimal system.

\section{LOWER NASOLACRIMAL SYSTEM (RETROGRADE ENDOSCOPY)}

Using the sagittal sections of the head and after removing the inferior turbinate, the lower nasolacrimal duct opening was identified by syringing through the canaliculus. Through the lower opening the nasolacrimal duct was gently probed before the fibrescopes were introduced. Again both types of fibrescopes could be passed easily through the nasolacrimal duct into the sac up to the level of the fundus of the lacrimal sac. Both fibrescopes provided good quality pictures allowing us to identify distinctly various structures. A small piece of steel wire $(0.1 \mathrm{~mm}$ diameter) with a gentle curve introduced into the $0.1 \mathrm{~mm}$ instrument channel of the XTUF-11 fibrescope gave it sufficient rigidity and curvature which facilitated exploration and visualisation of the inner aspect of the lacrimal sac. Following visualisation the lacrimal sac was dissected to reveal the features of its inner surface.

\section{Results}

Both prototype ultrathin fibrescopes PF-5 and XTUF-11 provided good quality magnified images which could be viewed constantly on the TV monitor and recorded simultaneously.
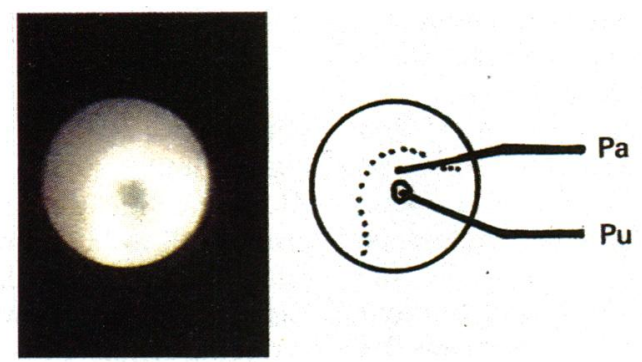

Fig $3 a$

$$
\text { Fig } 3 b
$$

Figure 3 (a) Appearance of the puncta just before insertion of the fibrescope. (b) $P a=$ papilla and $P u=$ punctum.
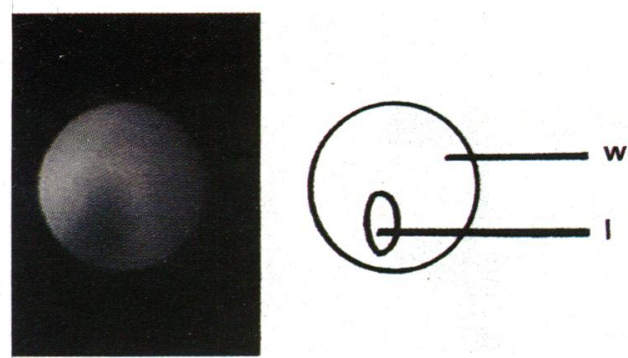

Fig $4 a$

Figure 4 (a) Endoscopic view of the canaliculus.

(b) $w=$ wall and l=lumen.
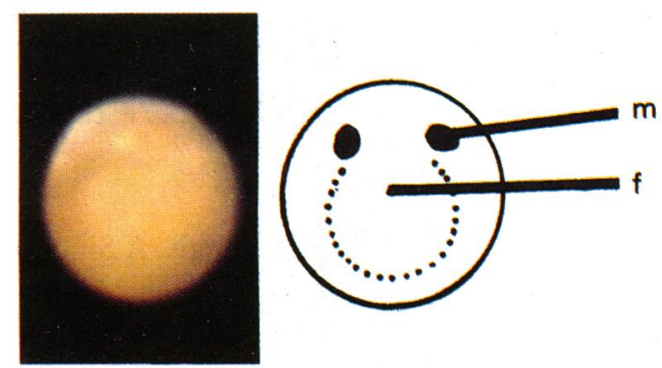

Fig $5 a$

Fig $5 b$

Figure 5 (a) Endoscopic view of the fundus of the lacrimal sac. (b) $m=$ mucosal fold and $f=$ fundus.

Fibrescope PF-5 provided superior quality images (Figs 5, 6, 9) to the fibrescope XTUF-11 (Figs 3, 4, 7). There was no other difference in the optical aspects of the image. The magnification is inversely proportional to the distance beween the tip of the fibrescope and the object to be viewed. The image is further magnified $1 \cdot 7 \times$ between the fibrescope and PVS-1 monitor.

The endoscopic findings are reported for each nasolacrimal structure separately. Figure 2 shows the various positions of the fibrescope tip in the nasolacrimal system in relation to Figures 3-11.

\section{PUNCTUM (FIG 3)}

Though this is strictly not an endoscopic picture it is included for the sake of completion. The papilla appeared as a ring of bright light which is surmounted by a dark appearing puncta (post dilatation).

\section{CANALICULUS (FIG 4)}

The 'tunnelling' effect is obvious. The canaliculus appeared as a dark hole. The obliquity of the fibrescope tip in relation to the canalicular wall gave it a sloping appearance and this also explains

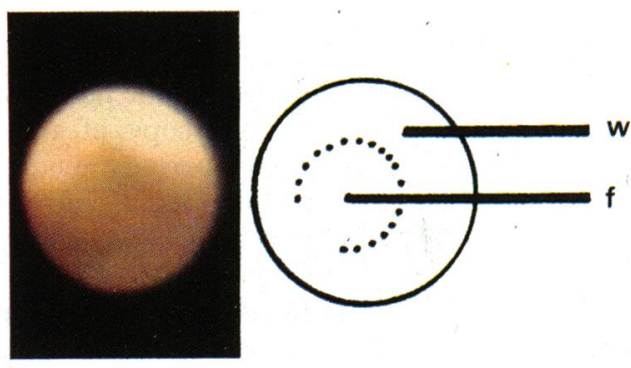

Fig $6 a$

Figure 6 (a) Endoscopic view of the side walls of the sac. (b) $w=$ wall and $f=$ fundus.
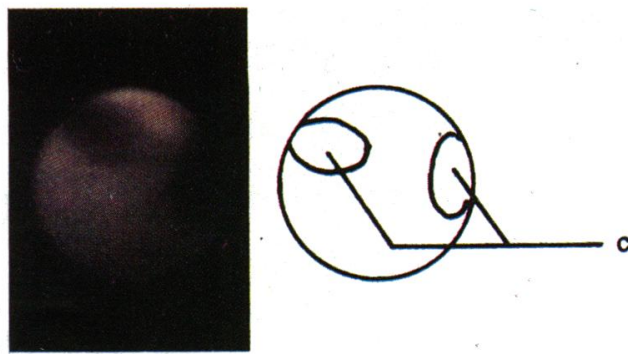

\section{Fig $7 a$}

Figure 7 (a) The opening of the canaliculi into the lacrimal sac. $(b) c=$ canalicular openings. 
Figure 8 (a) Appearance after dissection confirms separate openings of upper and lower canaliculi into the lacrimal sac. $(b) l=l i d$ margin, $a=$ anterior lacrimal crest, $c=$ canalicular openings, and $e=$ edge of the reflected anterior wall of the lacrimal sac.

Figure 9 (a) The opening of canaliculi into the lacrimal sac.

(b) $c=$ canalicular openings.

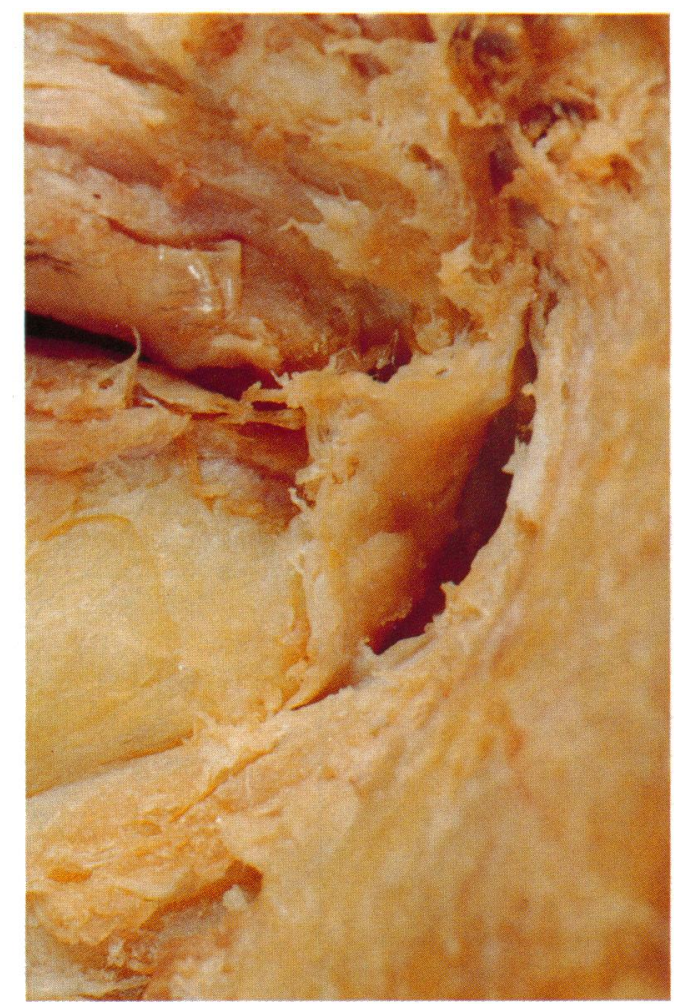

Fig $8 a$

the apparent eccentric location of the canalicular lumen.

LACRIMAL SAC (A) (FIG 5)

In this position the tip is very close to the fundus of the lacrimal sac. The central circular brighter zone corresponds to the inner concavity of the fundus. The two bright spots probably represent mucosal folds.

LACRIMAL SAC (B) (FIG 6)

As the tip was withdrawn slightly the appearance changed completely. The central brighter zone was replaced by a central dark zone surrounded by a bright area. This was more obvious in the upper half of the picture. As the tip moved away from the fundus the light being reflected by it reduced (and hence the bright to dark transition) and the light reflected from the side walls of the sac came into the view (outer bright area).

\section{LACRIMAL SAC (C) (FIG 7 AND FIG 9)}

With gentle manipulation of the tip it was possible to visualise the inner openings of the canaliculi. The upper and lower canaliculiopened
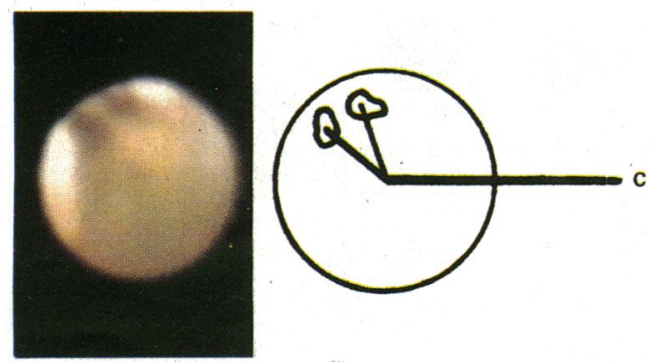

Fig $9 a$

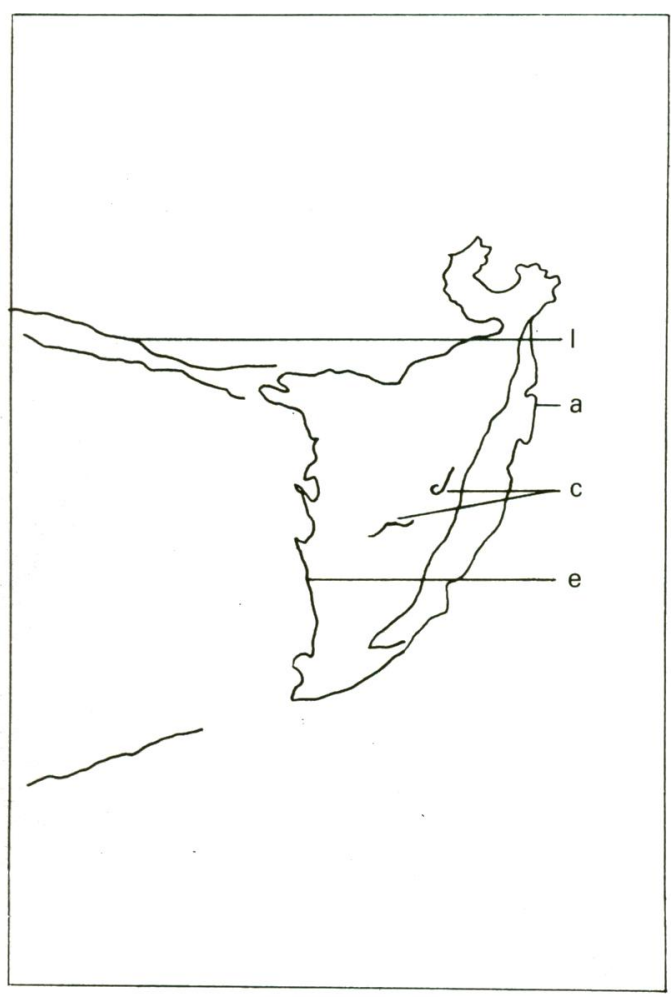

Fig $8 b$

separately into the lacrimal sac in both cases. On subsequent dissection this appearance was clearly confirmed in one case (Fig 8). However in the other case dissection presented an appearance of partial separation (Fig 10).

\section{NASOLACRIMAL DUCT (FIG 11)}

An oval appearance of the upper end of nasolacrimal duct was identified. The bright spot near the opening is either an artefact or a mucosal fold.

\section{Discussion}

The two prototype fibrescopes PF-5 and XTUF11 investigated in this study provided clear and reproducible images of the entire nasolacrimal system. Our findings demonstrate progress from previous attempts at endoscopic visualisation to include orthograde and retrograde endoscopy. This has enabled the visualisation of the inner openings of the canaliculi and of the nasolacrimal duct origin. In addition endoscopic appearances have been confirmed by dissection.

The fibrescopes used were thinner than the silicon tubing $(1 \cdot 19 \mathrm{~mm})$ suggested by Crawford ${ }^{10}$ for intubation of the lacrimal system. The outer diameters of the fibrescopes are compared with the size of silver probes (Fig 12). The fine calibre of these fibrescopes makes them inherently flexible. Because of this the fibrescopes could not be passed into the upper nasolacrimal opening during orthograde endoscopy and the inferior turbinate had to be removed to facilitate retrograde endoscopy. Though the quality of images generated by the fibrescope XTUF-11 were inferior to those of fibrescope PF-5, it may still be the preferred endoscope for two reasons. Firstly, greater thickness $(1 \cdot 1 \mathrm{~mm}$ compared 


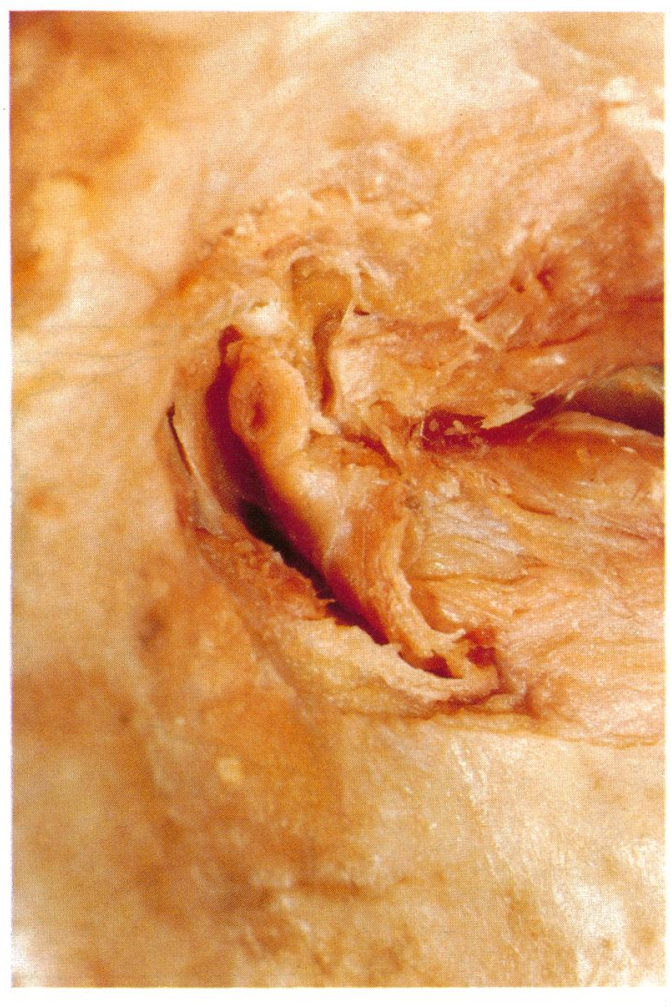

Fig $10 a$

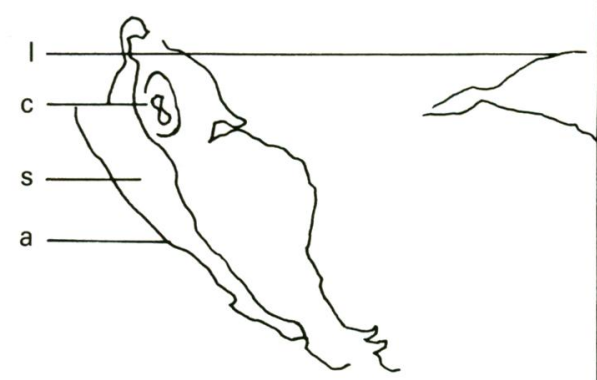

Fig $10 b$

Figure 10 (a) Partial separation of canalicular openings as seen on dissection. (b) $l=$ lid margin, $c=$ canalicular opening, $s=$ sac lumen, and $a=$ anterior lacrimal crest.
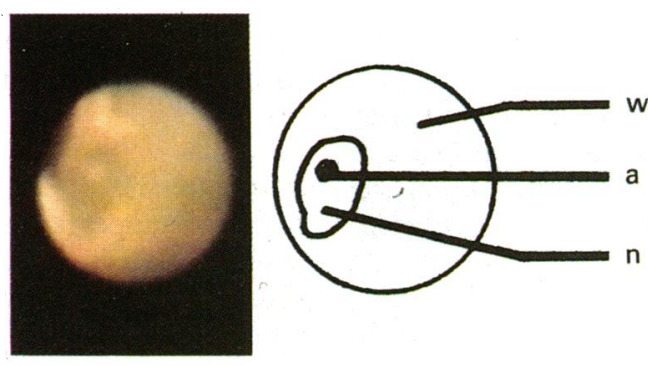

Fig $11 a$

Fig $11 b$

Figure 11 (a) The view of the nasolacrimal duct origin. (b) $w=$ lacrimal sac, $n=$ nasolacrimal duct opening, and $a=$ ? artefact.

with $0.5 \mathrm{~mm}$ ) provides increased rigidity and, secondly, it has a $0.1 \mathrm{~mm}$ wide instrument channel so that an introducer inserted through the tip of the fibrescope may be used to increase its rigidity. This instrument channel may offer interventional possibilities using a suitably designed laser probe. Under direct observation it may be possible to 'cut' through a block in the nasolacrimal duct. A high powered argon laser been kindly provided by UK and Fohn Weiss and Son Ltd, Milton Keynes, UK.)

\begin{tabular}{|c|c|c|c|c|c|c|}
\hline \multicolumn{2}{|c|}{} \\
\hline
\end{tabular}

coupled to a $300 \mu \mathrm{m}$ quartz fibreoptic has been used to create an intranasal dacryocystorhinostomy fistula in a patient undergoing endonasal laser dacryocystorhinostomy. "This is claimed to provide good haemostasis with reduced morbidity. Gonnering et $a l^{12}$ have reported excellent results in 18 patients undergoing transnasal laser assisted lacrimal procedures. They performed laser rhinostomy with carbon dioxide and potassium titanyl phosphate laser delivered through a $300-600 \mu \mathrm{m}$ fibre under video endoscopic visualisation. In addition chromiumsensitised, and thulium and holmium doped YAG laser (THC:YAG laser) coupled to a 480 $\mu \mathrm{m}$ optic probe can successfully create a limbal sclerostomy. ${ }^{13}$ The technique of probing used in children with epiphora is a 'blind' procedure. Bends in the course of the lower tear duct have been shown ${ }^{14}$ to exist and canalicular stenosis following probing for congenital nasolacrimal duct obstruction is a well known complication. ${ }^{15}$ Using the technique described by us, the upper nasolacrimal duct opening may be visualised and the block in the lower nasolacrimal duct treated under direct observation.

This technique, termed dacryocystoscopy, is still experimental. However, further studies on patients are planned to assess its full potential.

We are grateful to Mr Andrew Eakins of KeyMed Ltd, Southend, UK for providing the prototype fibrescopes and the recording equipment. We thank Mr J J Kanski, FRCS, for his critical reading of the manuscript.

The authors wish to declare that they have no commercial interest in any of the instruments/products used in this study.

1 Thorpe HE. Ocular endoscope: an instrument for the removal of intravitreous non-magnetic foreign bodies. Trans Am Acad Ophthalmol 1934; 39: 422-4.

2 Norris JL, Cleasby GW. An endoscope for ophthalmology. Am f Ophthalmol 1978; 85: 420-2. 
3 Norris JL, Cleasby GW, Nakanishi AS, Martin LJ. Intraocular endoscopic surgery. Am f Ophthalmol 1981; 91: 603-6

4 Norris JL, Cleasby GW. Endoscopic orbital surgery. Am $\mathcal{f}$ Ophthalmol 1981; 91: 249-52.

5 Classen M, Knyrim K, Seidlitz HK, Hagenmuller F. Electronic endoscopy: the latest technology. Endoscopy 1987; 19: 118-23

6 Eguchi S, Araie M. A new ophthalmic electronic videoendoscope system for intraocular surgery. Arch Ophthalmol 1990; 108: 1778-81

7 Cohen SW, Prescott R, Sherman M, Banko W, Castillejos ME. Dacryoscopy. Ophthalmic Surg 1979; 10: 57-63.

8 Ashenhurst AE, Hurwitz JJ. Lacrimal canaliculoscopy: development of the instrument. Can f Ophthalmol 1991; 26: 306-8.

9 Katz P. Salivary lithiasis: a new treatment approach Hospimedica 1991; 9: 28-33.
10 Crawford JS. Intubation of the lacrimal system. Ophthalmol Plast Reconstr Surg 1989; 5: 261-5.

11 Massaro BM, Gonnering RS, Harris GJ. Endonasal laser dacryocystorhinostomy. Arch Ophthalmol 1990; 108: 1172-6.

12 Gonnering RS, Lyon DB, Fisher JC. Endoscopic laserassisted lacrimal surgery. Am f Ophthalmol 1991; 111: 152assisted lacrimal surgery. Am f Ophthalmol 1991; 111: 152

13 Hoskins HD, Iwach AG, Drake MV, Schuster BL, Vassiliadis A, Crawford JB, et al. Subconjunctival THC:YAG laser limbal sclerostomy ab externo in the rabbit. Ophthalmic Surg 1990; 21: 589-92.

14 Busse H, Muller KM, Kroll P. Radiological and histologica findings of the lacrimal passages of newborns. Arch Ophthat mol 1980; 98: 528-32.

15 Lyon DB, Dotrzbach RK, Lemke BN, Gonnering RS Canalicular stenosis following probing for congenital nasolacrimal duct obstruction. Ophthalmic Surg 1991; 22: 22832. 